\title{
Libanios
}

\section{Für Religionsfreiheit, Recht und Toleranz}

Libanios' Rede für den Erhalt der heidnischen Tempel

Eingel., übers. u. m. interpretierenden Essays versehen v. Heinz-Günther

Nesselrath, Okko Behrends, Klaus S. Freyberger, Johannes Hahn, Martin Wallraff u.

Hans-Ulrich Wiemer

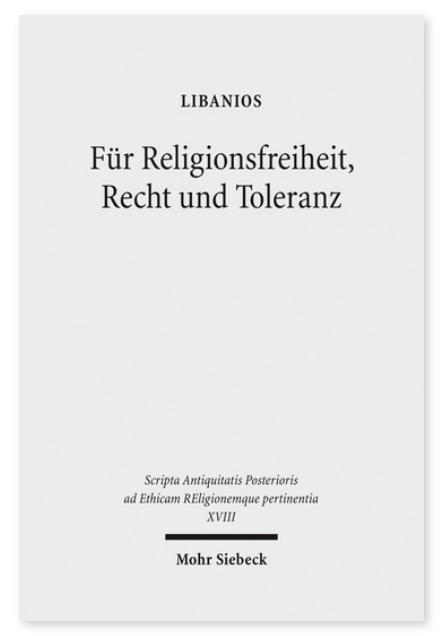

2011. XI, 276 Seiten. SAPERE XVIII

ISBN 978-3-16-156437-6

DOI 10.1628/978-3-16-156437-6

eBook PDF

ISBN 978-3-16-151002-1

fadengeheftete Broschur 29,00€
Der Band präsentiert die erste deutsche Übersetzung eines Textes, in dem sich der bedeutende spätantike Redner (und Redelehrer) Libanios von Antiocheia an den römischen Kaiser Theodosius (»den Großen«) wendet, um ihn dafür zu gewinnen, der Zerstörungswut fanatischer Christen (vor allem Mönche) Einhalt zu gebieten, die sich gegen die heidnischen Tempel in der Umgebung Antiocheias richtet. Libanios appelliert dabei an die Toleranz des christlichen Kaisers und weist auf die kulturgeschichtliche und identitätsstiftende Bedeutung der heidnischen Heiligtümer hin. Neben einer Einführung in den Autor, sein Werk und die hier präsentierte Schrift sowie dem Originaltext, seiner Übersetzung und ausführlichen Anmerkungen enthält der Band eine Reihe von Essays, die Libanios' Schrift aus der Perspektive verschiedener wissenschaftlicher Disziplinen zusätzlich beleuchten: das Verhältnis von Libanios' Rhetorik zum seinerzeit geltenden römischen Recht; Libanios' Einstellung zu und Stellung unter den christlichen römischen Kaisern seiner Zeit; die Rolle christlicher Mönche beim Rückgang der heidnischen Kulte in der Spätantike; archäologische Erkenntnisse zum Schicksal heidnischer Heiligtümer nach Erlöschen der Kulte; das Phänomen religiöser Intoleranz in der Spätantike. Dank diesen Beiträgen kann die Bedeutung der Schrift des Libanios in ihrem rechts-, kultur-, religions- und allgemeinhistorischem Kontext erstmals umfassend gewürdigt werden.

Libanios Keine aktuellen Daten verfügbar.

Okko Behrends war von 1975 bis 2007 Inhaber des Lehrstuhls für Römisches Recht, Bürgerliches Recht und Neuere Privatrechtsgeschichte an der Juristischen Fakultät der Georg-August-Universität Göttingen; seit 1982 Mitglied der Akademie der Wissenschaften zu Göttingen; 2009 Ehrendoktor der Juristischen Fakultät Stockholm.

Klaus S. Freyberger war von 2002 bis 2013 wissenschaftlicher Direktor an der Abteilung Rom des Deutschen Archäologischen Instituts. Seine Forschungsschwerpunkte lagen vornehmlich auf der antiken Topographie und Siedlungsgeschichte in Syrien und Rom. Forschungsprojekte beinhalteten die städtischen Zentren der Kaiserzeit in Südsyrien, besonders Qanawat, hellenistische und kaiserzeitlicheTempelbauten in der östlichen Mittelmeerwelt sowie republikanische und kaiserzeitliche Repräsentationsbauten auf dem Forum Romanum in Rom.

Johannes Hahn Geboren 1957; Professor für Alte Geschichte an der Universität Münster.

Heinz-Günther Nesselrath Geboren 1957; 1976-81 Studium der Klassischen Philologie und der Alten Geschichte an der Universität zu Köln; 1981 Promotion; 1987 Habilitation; 1992-2001 vollamtlicher Professor für Klass. Philologie an der Universität Bern; seit 2001 Universitätsprofessor für Klass. Philologie an der Georg-August-Universität Göttingen.

Martin Wallraff Geboren 1966; 1996 Promotion; 2000 Habilitation; Professur für Ältere Kirchengeschichte an der EvangelischTheologischen Fakultät der Ludwig-Maximilians-Universität München.

https://orcid.org/0000-0003-1085-8601

Hans-Ulrich Wiemer ist Inhaber des Lehrstuhls für Alte Geschichte an der Friedrich- Alexander-Universität Erlangen-Nürnberg und korrespondierendes Mitglied des Deutschen Archäologischen Instituts. Seine Forschungsschwerpunkte liegen vor allem in der Geschichte des Hellenismus und der Spätantike.

Jetzt bestellen:

https://mohrsiebeck.com/buch/fuer-religionsfreiheit-recht-und-toleranz-9783161564376?no_cache=1

order@mohrsiebeck.com

Telefon: +49 (0)7071-923-17

Telefax: $+49(0) 7071-51104$ 